and they breed defensive practices in responses to too much (adverse) publicity.

Looking at the language he uses to express these concerns, however, one detects an underlying anxiety about the place of the bereaved 'secondary' victim in this process and, perhaps, a reluctance to acknowledge their right to express their anger and pain in public. Hence Jayne Zito, a campaigner and professional in her own right, as well as a victim, is described as 'distraught'; Muijen's proposed new system for inquiries would inevitably lead, he says, to "various parties screaming 'Cover-up'", and too many people describing themselves as experts are not only "quite prepared to rub salt into the wound in return for a media slot" but seem also to be responsible, somehow, for the current "spiral of inquiries". Surely the number of inquiries attempts to reflect the number of homicides, not the publicity devoted to them?

Two things have to be remembered. The first is that this country's toleration of victims and grief is generally very poor. Their occasional public outbursts of outrage, anguish and pain are often experienced as irrational, hysterical and sometimes terrifying. The second is that given the state of the Law of Negligence, it seems as if these secondary victims are not currently owed a duty of care and are unable to take legal action against those agencies who may have been negligent in the management of the patient who went on to commit the homicide. Although he does not explicitly address the legal issue, Dr Grounds' powerful response to Dr Muijen (Psychiatric Bulletin, 21, March 1997, 134-135), makes it clear that independent inquiries are the essential, indeed the only, forms of redress and understanding available to bereaved families. To bureaucratise the process in the way proposed would, I suggest, add further insult to injury.

Michael Howlett, Director, The Zito Trust

\section{London bed fever}

Sir: A recent survey of London's acute mental health service revealed a bed occupancy of $113 \%$ for Greater London (Hollander et al, 1996). At the same time in Brent (which is an inner-urban London borough of 240000 people with a Jarman UPA8 score of 28 , served by 94 acute admission beds (105\% occupancy)) the local Health Commissioning Agency were supporting around 30 extra contractural referral (ECR) beds at a minimum cost of approximately $\$ 100000$ per month. The authors were concerned that such high occupancy figures might be disguising a problem of high ECR usage that was not peculiar to Brent. With this in mind we attempted to ascertain acute ECR usage across the capital.

To start with we identified local ECR usage and expenditure. Unfortunately, our figures did not tally with our local purchaser's receipts, though there was a rough approximation. We then attempted the same exercise on a broader scale.

It transpired that other trusts within Greater London either did not know how many ECRs they had or had no idea what they were costing. It is of course possible that commercial interests resulting from internal market forces prevented them from sharing this information.

We then attempted to ascertain the problem from the purchasers' perspective. Initially we approached the Health Authorities directly. They did not know what they were spending on ECRs (or would not tell us). Our own Health Authority tried to assist by approaching the other purchasing agencies on our behalf. They still could not tell us. Lastly, we asked North Thames Regional Office: we were informed that such information is no longer monitored by the NHS Executive.

Taking Britain's conurbations as a whole, it is likely that there is a flow of tens of millions of pounds each year from deprived urban areas to suburban and rural areas and to the private sector. This uncontrollable switch of resources compromises the community care approach of acute mental health services and brings into question the policy of planning for geographical equity in mental health care.

This unplanned disinvestment in local services has profound consequences. Commissioning agencies have to cut budgets beyond those for merely mental health services. Such short term exigencies result in forgone opportunities; the loss of resources and the diversion of managerial attention lead to delays in service improvements. Further hidden costs include those of transferring patients and monitoring their contracts, the problems of poorly planned follow-up and the likelihood of readmission rates.

Clinicians are being asked to share clinical information about their patients across geographical boundaries and between various agencies. There are good grounds for this, such as comprehensive planning of patient care and integrated and efficient working practices. In contrast it seems that the notion of planning service needs at the population level is of little interest to those who commission services.

Hollander, D., Powell, R. \& Tobiansky, R. (1996) Bed occupancy in psychiatric units in Greater London is $113 \%$. British Medical Journal, 313. 166.

PAUL MALLETT, Consultant Psychiatrist and ROBIN Powell, Consultant Psychiatrist, North West London Mental Health NHS Trust, Park Royal Centre for Mental Health, Central Middlesex Hospital, Acton Lane, London NW10 7NS 